\title{
Synthesis of Vertically Aligned Carbon Nanotubes on Silicalite-1 Monolayer-Supported Substrate
}

\author{
Wei Zhao, ${ }^{1}$ Bijay Basnet, ${ }^{2}$ Sukyoung Kim, ${ }^{1}$ and Ik Jin Kim² \\ ${ }^{1}$ School of Materials Science \& Engineering, Yeungnam University, Gyeongsan City, Gyeongbuk 712-749, Republic of Korea \\ ${ }^{2}$ Department of Materials Science and Engineering, Institute of Processing and Application of Inorganic Materials, \\ Hanseo University, Seosan City, Chungnam 356-706, Republic of Korea
}

Correspondence should be addressed to Sukyoung Kim; sykim@yu.ac.kr and Ik Jin Kim; ijkim@hanseo.ac.kr

Received 19 October 2013; Accepted 23 December 2013; Published 10 February 2014

Academic Editor: Alireza Talebitaher

Copyright (C) 2014 Wei Zhao et al. This is an open access article distributed under the Creative Commons Attribution License, which permits unrestricted use, distribution, and reproduction in any medium, provided the original work is properly cited.

\begin{abstract}
Monodisperse magnetic $\mathrm{Fe}_{3} \mathrm{O}_{4}$ nanoparticles (NPs) with the size of ca. $3.5 \mathrm{~nm}$ were prepared and used as the catalysts for the synthesis of vertically aligned carbon nanotube (VACNT) arrays. A silicalite-1 microcrystal monolayer was used as the support layer between catalyst NPs and the silicon substrate. Compared to our previous report which used radio-frequency- (rf-) sputtered $\mathrm{Fe}_{2} \mathrm{O}_{3}$ film as the catalyst, $\mathrm{Fe}_{3} \mathrm{O}_{4}$ NPs that were synthesized by wet chemical method showed an improved catalytic ability with less agglomeration. The silicalite-1 crystal monolayer acted as an effective "buffer" layer to prevent the catalyst NPs from agglomerating during the reaction process. It is believed that this is the first report that realizes the vertical alignment of CNTs over the zeolite monolayer, namely, silicalite-1 microcrystal monolayer, instead of using the intermediate anodic aluminum oxide (AAO) scaffold to regulate the growth direction of CNT products.
\end{abstract}

\section{Introduction}

Carbon nanotubes (CNTs) have become the target of intense study owing to their unique nanostructure-dependent physical and chemical properties [1]. These distinctive characteristics arise from their different atomic structures and sizes. For example, CNTs can be either metallic or semiconducting according to their helicity and diameter [2]. The latter can also influence their mechanical properties, which can have a significant impact on their promising applications in many potential fields, such as nanoelectronic devices [3], composite materials [4], hydrogen storage media [5], and field emission devices [6].

Although not all the reported applications will require large scale CNT use, there are still some where the mass production of CNTs is strongly in demand. As a result, there is a need for facile and inexpensive approaches for the large scale production of CNTs. For some applications, such as scanning probes [7] and sensors [8] and field emitters in nanoelectronics [9], vertically aligned CNT (VACNT) arrays are particularly required through control and optimization of the diameter, wall structure, and areal density of CNTs.
A range of techniques have been developed for VACNT synthesis, such as HiPco [10], fluidized bed [11], and chemical vapor deposition (CVD) [12], and CVD has proven to be the most effective one. Although the growth of VACNT reduces or eliminates the necessity of postprocessing the as-produced CNTs, it is still dependent on the use of expensive substrate materials and deposition equipment, such as electron beam evaporation, which reduces the potential for scaling-up CNT production.

An important issue impeding such growth is the limited thermal stability of nanoparticles (NPs), because they tend to agglomerate into larger ones at elevated temperatures through atomic interdiffusion, also known as "Ostwald ripening" [13]. This will result in catalyst clusters without monodisperse diameters and quantifiable areal densities so that it is hardly to achieve self-oriented CNTs perpendicular to the substrate. Therefore, an efficient substrate that can stabilize catalyst NPs at high temperatures is necessary. Many templates, such as porous anodic aluminum oxide (AAO) [14] and block copolymer micelles [15], have been used. 


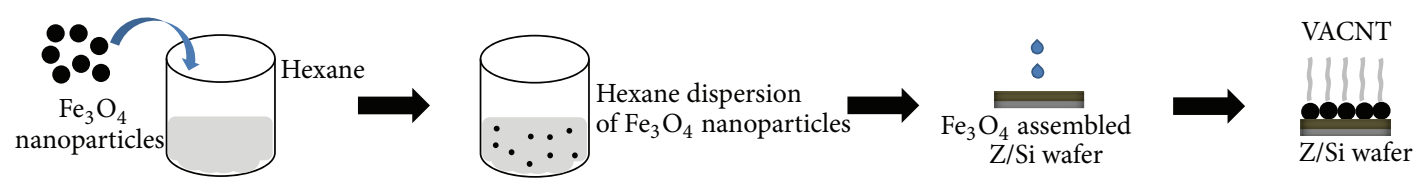

FIGURE 1: Synthesis of VACNT arrays on a silicalite-1 monolayer-assembled $\mathrm{Si}$ wafer using the synthesized $\mathrm{Fe}_{3} \mathrm{O}_{4} \mathrm{NPs}_{\text {as }}$ the catalysts.

In this study, we reported a simple approach that used premade monodisperse $\mathrm{Fe}_{3} \mathrm{O}_{4}$ nanoparticles (NPs), $\sim 3.5 \mathrm{~nm}$ in size, as the catalysts and self-assembled silicalite- 1 monolayer as the support layer to synthesize VACNT arrays by catalytic CVD (CCVD). The difference of this study from others is that the silicalite-1 microcrystals were self-assembled on the silicon ( $\mathrm{Si}$ ) wafers in the form of a monolayer to be used as a "buffer" layer, instead of AAO scaffold [16] or $\mathrm{Al}_{2} \mathrm{O}_{3}$ layer [17], to support $\mathrm{Fe}_{3} \mathrm{O}_{4}$ catalyst NPs. As far as we know, this is the first report on the synthesis of VACNTs using well-oriented zeolite monolayer to replace other commonly-used templates mentioned above as the support layer.

\section{Experimental}

2.1. Preparation of $\mathrm{Fe}_{3} \mathrm{O}_{4}$ NPs. Monodisperse $\mathrm{Fe}_{3} \mathrm{O}_{4} \mathrm{NPs}$ were prepared using the method reported elsewhere [18]. Briefly, $1 \mathrm{mmol} \mathrm{Fe}(\mathrm{acac})_{3}, 5 \mathrm{mmol}$ 1,2-hexadecanediol (HDD), $4.5 \mathrm{mmol}$ oleic acid (OA), $3 \mathrm{mmol}$ oleylamine $(\mathrm{OAm})$, and $10 \mathrm{~mL}$ phenyl ether $(\mathrm{PE})$ were mixed and heated under reflux for $30 \mathrm{~min}$ with vigorous stirring under a mild nitrogen $\left(\mathrm{N}_{2}\right)$ flow. Subsequently, the black mixture was cooled to room temperature by removing the heat source. The product was then precipitated with ethanol, centrifuged, and redispersed several times in hexane, resulting in a fine hexane dispersion of $\mathrm{Fe}_{3} \mathrm{O}_{4}$ NPs.

2.2. Self-Assembly of Silicalite-1 Monolayer onto the Si Wafer. A silicalite-1 microcrystal monolayer was simply assembled using a previously reported procedure [19]. Briefly, Si wafers $(1 \mathrm{~cm} \times 1 \mathrm{~cm})$ were cleaned thoroughly, and immersed in a diluted hydrofluoric acid solution to eliminate the oxidized surface. They were then rinsed with distilled (DI) water and dried in a high-purity $\mathrm{N}_{2}$ steam. To self-assemble the silicalite-1 microcrystals on the Si wafer, an ethanol solution of poly(ethylenimine) (PEI) was first spin-coated on the substrate. Approximately $5 \mathrm{mg}$ of silicalite- 1 microcrystals was gently rubbed on the wafer by a finger for $30 \mathrm{~s}$ to form a monolayer. Mild sonication of the coated wafer for several seconds in DI water is essential for removing the crystals physically-adsorbed on the monolayer. Subsequently, the silicalite-1-assembled Si wafers were dried by $\mathrm{N}_{2}$, and they are signified as Z/Si.

2.3. Synthesis of VACNT Arrays by CCVD. To prepare the catalyst-supported substrate, one drop of a hexane dispersion of $\mathrm{Fe}_{3} \mathrm{O}_{4} \mathrm{NPs}$ was dropped onto $\mathrm{Z} / \mathrm{Si}$. The substrate is designated $\mathrm{Fe}_{3} \mathrm{O}_{4} / \mathrm{Z} / \mathrm{Si}$. After being dried in air for a short time, the substrate was inserted into a horizontal electric tubular furnace. Under an $\mathrm{Ar} / \mathrm{H}_{2}$ atmosphere, the substrates were heated from room temperature to $973 \mathrm{~K}$. After pretreatment for $10 \mathrm{~min}, \mathrm{C}_{2} \mathrm{H}_{2}(10 \mathrm{sccm})$ was fed into the furnace with an $\mathrm{Ar} / \mathrm{H}_{2}(200 \mathrm{sccm})$ flow at this temperature for CNT synthesis and growth. $\mathrm{C}_{2} \mathrm{H}_{2}$ was then cut off and the reactor was cooled to room temperature under an $\mathrm{Ar} / \mathrm{H}_{2}$ flow. Figure 1 shows the process for synthesizing the VACNT arrays.

\section{Characterization}

Powder X-ray diffraction (XRD, Rigaku D/max 2500 VL/PC) was performed using a $\mathrm{Cu} \mathrm{K} \alpha$ radiation $(40 \mathrm{kV}, 40 \mathrm{~mA}, k$ $=1.5418 \AA$ ). The patterns were recorded from 10 to $80^{\circ} 2 \theta$ in $0.04^{\circ}$ steps with a counting time of $2 \mathrm{~s}$ per step. Field emission scanning electron microscopy (FESEM) images were collected on a SEM LEO 1530 VP microscope. High resolution transmission electron microscopy (HRTEM, JEOL JEM-3011) was carried out at an accelerating voltage of $200 \mathrm{kV}$. The samples were prepared by evaporating drops of a sonicated ethanol suspension onto a carbon-coated lacy film supported on a $3 \mathrm{~mm}$ diameter, 300-mesh copper grid.

\section{Results and Discussion}

The synthesized $\mathrm{Fe}_{3} \mathrm{O}_{4}$ NPs were characterized by TEM, as shown in Figure 2. Figures 2(a) and 2(c) showed low and high magnification HRTEM images of the as-produced $\mathrm{Fe}_{3} \mathrm{O}_{4} \mathrm{NPs}$ without further size-sorting, respectively. Clear lattice fringes were observed (Figure 2(c)), indicating a single crystalline structure [20]. The distance between the two adjacent planes was $\sim 2.52 \AA$, which corresponds to the (311) plane of the FCC structured $\mathrm{Fe}_{3} \mathrm{O}_{4}$.

The selected area electron diffraction (SAED) patterns revealed six distinct rings, and the calculated d-spacings matched well with the interplanar distances of face-centered cubic (FCC) $\mathrm{Fe}_{3} \mathrm{O}_{4}$, as shown in Figure 2(b).

More than 100 NPs were measured to obtain the size distribution, which is shown in Figure 3. The particles were monodisperse with a size of approximately $3.5 \mathrm{~nm}$, which is also in accordance with the TEM results shown above.

According to a previous report [19], the silicalite-1 crystals with a mean size of $1.5 \times 1.1 \times 0.6 \mu \mathrm{m}^{3}$ were assembled onto a $\mathrm{Si}$ wafer in the form of a monolayer by finger rubbing, as shown in Figures 4(a) and 4(b). Compared to the random orientation of pristine silicalite-1 crystals shown in the inset of Figure 4(a), Figures 4(a) and 4(b) show crystals all with b-axes perpendicular to the Si wafer surface, which was confirmed by the cross-sectional view, as shown in Figure 4(c). In addition, almost the entire Si surface was covered with the crystals. The same results were verified by 


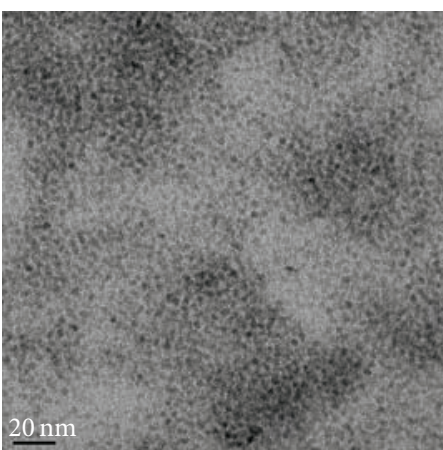

(a)

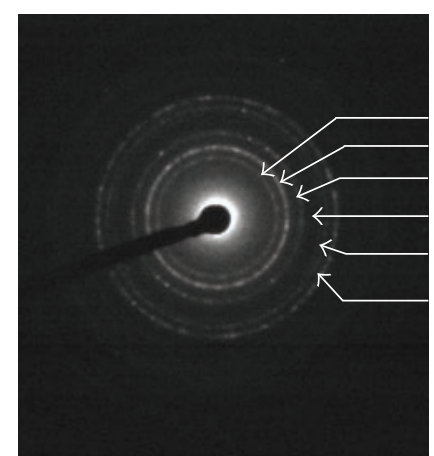

(b)

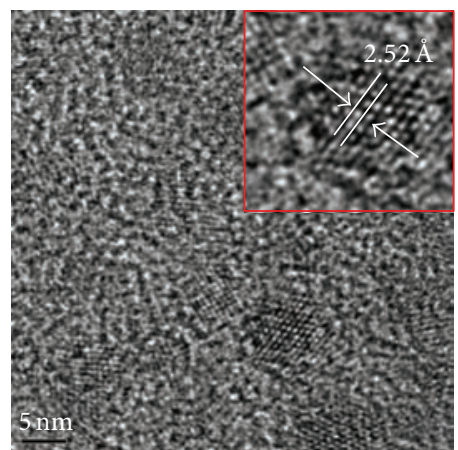

(c)

Figure 2: (a) Low magnification TEM image, (b) selected area electron diffraction pattern, and (c) high magnification TEM image of synthesized $\mathrm{Fe}_{3} \mathrm{O}_{4}$ NPs (inset: a single $\mathrm{Fe}_{3} \mathrm{O}_{4} \mathrm{NP}$ ).

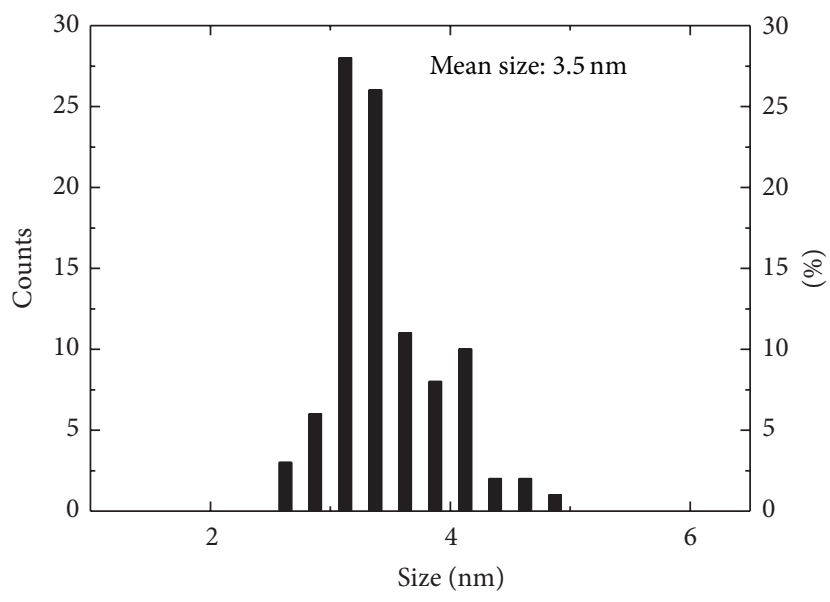

FIgURE 3: Size distribution of the synthesized $\mathrm{Fe}_{3} \mathrm{O}_{4}$ NPs.

XRD patterns of monolayer-assembled and pristine silicalite1 crystals, as shown in Figure 4(d) and its inset, respectively. A comparison between the two patterns revealed that only five $(0 k 0)$ reflection planes $(k=2,4,6,8$, and 10) at 8.9, $17.8,26.8,36.0$, and $45.5^{\circ} 2 \theta$ were shown after the assembling of the silicalite-1 crystal monolayer, as shown in Figure 4(d), indicating the uniform orientation of the microcrystals on the Si wafer. This is obviously different from that of the pristine random crystals, shown by the XRD pattern in the inset of Figure $4(\mathrm{~d})$.

VACNT arrays on the Z/Si were synthesized according to the experimental procedures described above. Figure 5 shows representative FESEM images of the samples. As shown in Figure 5(a), a CNT "carpet" formed on top of the Z/Si. From the view of the locally enlarged area, as presented in Figure 5(b), the CNTs exhibited a vertical orientation to a large extent. In addition, the CNTs synthesized were typically multiwalled CNTs, and their mean inner and outer diameters were estimated to be 7.5 and $17.5 \mathrm{~nm}$, respectively, as shown in the inset of Figure 5(b). Compared with our previous study [19] that used radio-frequency- (rf-) sputtered $\mathrm{Fe}_{2} \mathrm{O}_{3}$ film as the catalysts, the CNTs synthesized in this study showed a great improvement. As shown in Figure S1(a) in the Supplementary Material available online at http://dx.doi.org/10.1155/2014/327398, CNTs synthesized from rf-sputtered $\mathrm{Fe}_{2} \mathrm{O}_{3}$ film showed random growth directions and distinct diameter distribution. Quite a number of CNTs grew directly on the Si wafer surface between silicalite1 crystals, and even those grown on the silicalite-1 crystals could hardly keep vertical-alignment tendency, as shown in Figure S1(b). Moreover, some fiber-like thick products were observed, as shown in Figure S1(a), indicating the formation of more defects and broad diameter distribution. One explanation for this phenomenon is the serious agglomeration of catalyst NPs [19], which could be observed from Figure S2. In Figure S2(a), the continuous $\mathrm{Fe}_{2} \mathrm{O}_{3}$ film showed domains of $\mathrm{Fe}_{2} \mathrm{O}_{3}$, with the size being approximately $15 \sim 18 \mathrm{~nm}$, which seemed enough for CNT synthesis. However, in Figure S2(b), the $\mathrm{Fe}_{2} \mathrm{O}_{3}$ particles showed a strong agglomeration, leading to even large clusters. As a result, it not only led to a lower catalytic ability for CNT formation but also shrank areal density of catalyst NPs, which could compromise their initial crowding and continuous growing upward [21]. In addition, when the catalyst clusters were too large, the role of silicalite1crystal layer became insignificant because the pore size of the silicalite- 1 crystals is just a few Angstroms. In contrast, in this study, monodisperse $\mathrm{Fe}_{3} \mathrm{O}_{4}$ NPs with the $3.5 \mathrm{~nm}$ size were used, aiming at increasing the areal density [22] of the catalyst NPs on the substrate. Moreover, $\mathrm{H}_{2}$ used in this study reduced $\mathrm{Fe}_{3} \mathrm{O}_{4}$ NPs to discrete Fe NPs, preventing them from agglomeration [23] and also reduced the rate of carbon production by dehydrogenation [24] so that the more ordered and thermodynamically stable CNTs can be produced rather than the less ordered and unstable soot and carbon fibers obtained in our previous study. As shown in Figure 5, it is confirmed that main products were MWCNTs without thicker carbon fibers, and synthesized CNTs showed a uniform vertical-alignment tendency, indicating the advantage of using smaller monodisperse catalyst NPs over rf-sputtered ones and that of adding $\mathrm{H}_{2}$.

The mean diameter of the synthesized CNTs was several times larger than the original NP size, which can be explained by unavoidable coalescence during the heat-treatment. 


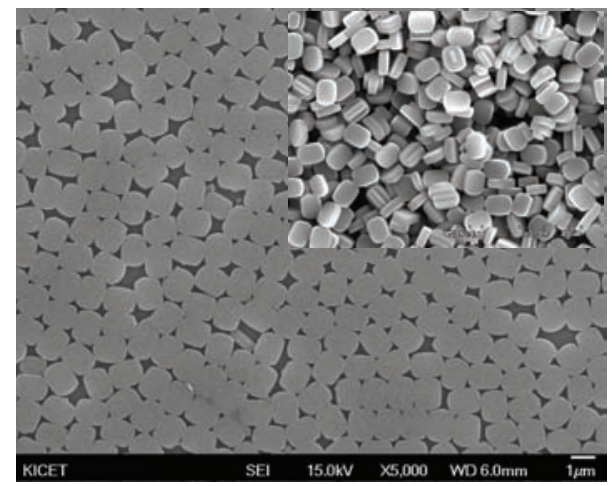

(a)

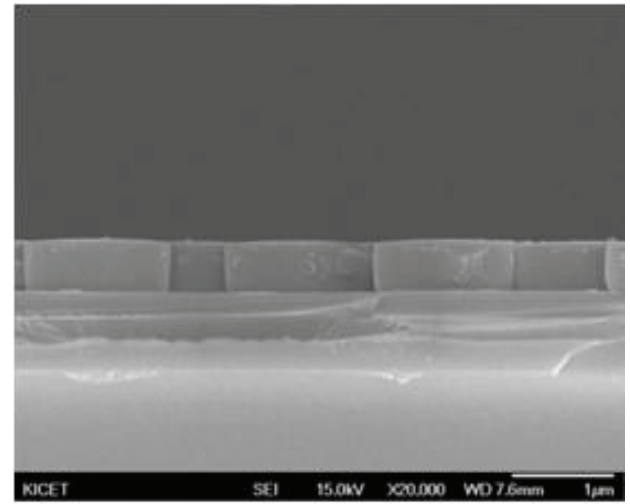

(c)

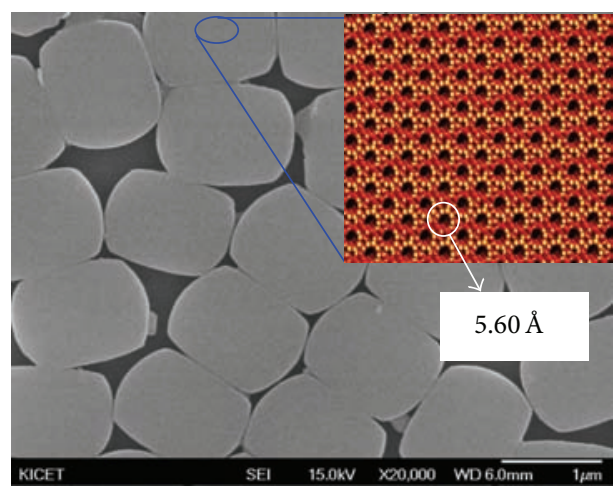

(b)

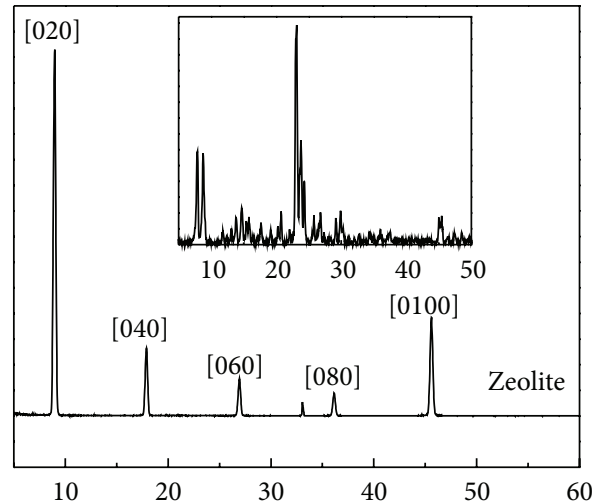

(d)

FIGURE 4: (a) Low magnification SEM image of the Z/Si substrate (vertical view) and as-synthesized silicalite-1 crystals (inset), (b) high magnification SEM image of uniformly oriented Z/Si substrate (vertical view) and the pore structure on the (100) sheet (inset), (c) SEM image of uniformly-oriented Z/Si substrate (sectional view), and (d) XRD pattern of uniformly-oriented silicalite-1 monolayer-assembled Si wafer and as-synthesized silicalite-1 crystals (inset).

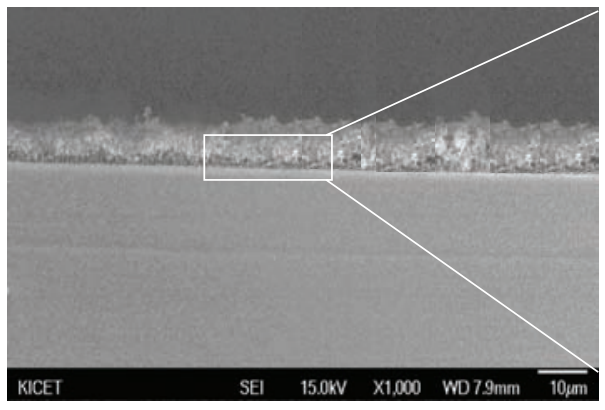

(a)

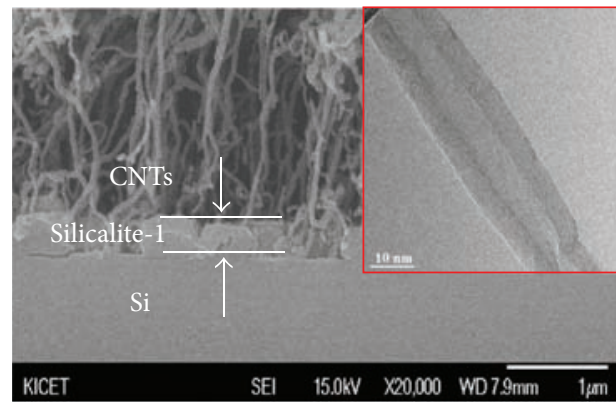

(b)

FIGURE 5: Cross-sectional SEM images of vertically aligned carbon nanotube arrays synthesized from $\mathrm{Fe}_{3} \mathrm{O}_{4} / \mathrm{Z} / \mathrm{Si}$. (a) Macroscale view and (b) enlarged view of the selected area (inset: synthesized MWCNT along with the mean diameter).

Despite this, the relatively thinner diameters compared to the previous results suggest that silicalite- 1 crystals played a significant role in stabilizing and isolating the catalyst NPs to prevent them from coalescing under elevated temperatures. Therefore, the high density of NPs on the substrate could be retained to guarantee the synthesis of VACNT arrays with thinner diameters.

\section{Conclusions}

In this study, we reported the synthesis of vertically-aligned carbon nanotube (VACNT) arrays by using monodisperse magnetic $\mathrm{Fe}_{3} \mathrm{O}_{4}$ NPs with the size of ca. $3.5 \mathrm{~nm}$ as the catalysts and a silicalite-1 microcrystal monolayer as the "buffer" layer between catalyst NPs and the silicon substrate. 
As far as we know, this is the first report succeeding in VACNT synthesis using the assembled silicalite-1 monolayer as the support layer rather than intermediate AAO scaffold and others. $\mathrm{Fe}_{3} \mathrm{O}_{4} \mathrm{NPs}$ of $3.5 \mathrm{~nm}$ size that were synthesized by wet chemical method showed an improved catalytic ability and provided a large catalyst surface density. And the silicalite-1 crystal monolayer acted as an effective "buffer" layer to stabilize the catalyst NPs from agglomerating during the reaction process. An ensemble of VACNT arrays was obtained despite some disturbance of a small number of random CNTs catalyzed from the NPs deposited directly on the Si wafer between the gaps of the silicalite-1 crystals.

\section{Conflict of Interests}

The authors declare that there is no conflict of interests regarding the publication of this paper.

\section{Acknowledgments}

This study was supported by a grant from the 2012 Fundamental R\&D Program of Hanseo University, Korea, and by the National Research Foundation of Korea (NRF) grant funded by the Korean government (MEST).

\section{References}

[1] C. H. Yu, L. Shi, Z. Yao, D. Li, and A. Majumdar, "Thermal conductance and thermopower of an individual single-wall carbon nanotube," Nano Letters, vol. 5, no. 9, pp. 1842-1846, 2005.

[2] T. W. Odom, J.-L. Huang, P. Kim, and C. M. Lieber, "Structure and electronic properties of carbon nanotubes," Journal of Physical Chemistry B, vol. 104, no. 13, pp. 2794-2809, 2000.

[3] A. Bachtold, P. Hadley, T. Nakanishi, and C. Dekker, "Logic circuits with carbon nanotube transistors," Science, vol. 294, no. 5545, pp. 1317-1320, 2001.

[4] P. Calvert, "Nanotube composites: a recipe for strength," Nature, vol. 399, no. 6733, pp. 210-211, 1999.

[5] A. C. Dillon, K. M. Jones, T. A. Bekkedahl, C. H. Kiang, D. S. Bethune, and M. J. Heben, "Storage of hydrogen in single-walled carbon nanotubes," Nature, vol. 386, no. 6623, pp. 377-379, 1997.

[6] W. I. Milne, K. B. K. Teo, G. A. J. Amaratunga et al., "Carbon nanotubes as field emission sources," Journal of Materials Chemistry, vol. 14, no. 6, pp. 933-943, 2004.

[7] T. W. Odom, J. H. Hafner, and C. M. Lieber, "Scanning probe microscopy studies of carbon nanotubes," in Carbon Nanotubes, vol. 80 of Topics in Applied Physics, pp. 173-211, Springer, Berlin, Germany, 2001.

[8] G. Chen, T. M. Paronyan, E. M. Pigos, and A. R. Harutyunyan, "Enhanced gas sensing in pristine carbon nanotubes under continuous ultraviolet light illumination," Scientific Reports, vol. 2, article 343, pp. 1-7, 2012.

[9] A. D. H. Walt, A. Châtelain, and D. Ugarte, "A carbon nanotube field-emission electron source," Science, vol. 270, no. 5239, pp. 1179-1180, 1995.

[10] P. Nikolaev, M. J. Bronikowski, R. K. Bradley et al., "Gasphase catalytic growth of single-walled carbon nanotubes from carbon monoxide," Chemical Physics Letters, vol. 313, no. 1-2, pp. 91-97, 1999.
[11] Q. Zhang, M.-Q. Zhao, J.-Q. Huang et al., "Vertically aligned carbon nanotube arrays grown on a lamellar catalyst by fluidized bed catalytic chemical vapor deposition," Carbon, vol. 47, no. 11, pp. 2600-2610, 2009.

[12] R. Xiang, G. Luo, Z. Yang, Q. Zhang, W. Qian, and F. Wei, "Large area growth of aligned CNT arrays on spheres: cost performance and product control," Materials Letters, vol. 63, no. 1, pp. 84-87, 2009.

[13] X. Wang, P. J. Krommenhoek, P. D. Bradford et al., "Coating alumina on catalytic iron oxide nanoparticles for synthesizing vertically aligned carbon nanotube arrays," ACS Applied Materials \& Interfaces, vol. 3, no. 11, pp. 4180-4184, 2011.

[14] E. J. Bae, W. B. Choi, K. S. Jeong et al., "Selective growth of carbon nanotubes on pre-patterned porous anodic aluminum oxide," Advanced Materials, vol. 14, no. 4, pp. 277-279, 2002.

[15] R. D. Bennett, G. Y. Xiong, Z. F. Ren, and R. E. Cohen, "Using block copolymer micellar thin films as templates for the production of catalysts for carbon nanotube growth," Chemistry of Materials, vol. 16, no. 26, pp. 5589-5595, 2004.

[16] P. Hou, C. Liu, C. Shi, and H. Cheng, "Carbon nanotubes prepared by anodic aluminum oxide template method," Chinese Science Bulletin, vol. 57, no. 2-3, pp. 187-204, 2012.

[17] K. Hata, D. N. Futaba, K. Mizuno, T. Namai, M. Yumura, and S. Iijima, "Water-assisted highly efficient synthesis of impurityfree single-walled carbon nanotubes," Science, vol. 306, no. 5700, pp. 1362-1364, 2004.

[18] S. Sun, H. Zeng, D. B. Robinson et al., "Monodisperse $\mathrm{MFe}_{2} \mathrm{O}_{4}$ $(\mathrm{M}=\mathrm{Fe}, \mathrm{Co}, \mathrm{Mn})$ Nanoparticles," Journal of the American Chemical Society, vol. 126, no. 1, pp. 273-279, 2004.

[19] W. Zhao, H. S. Kim, D. N. Seo, A. Pokhrel, H. T. Kim, and I. J. Kim, "Assembled monolayer of silicalite-1-supported iron oxide nanoparticles for carbon nanotube growth by catalytic chemical vapour deposition," Asian Journal of Chemistry, vol. 24, no. 11, pp. 5249-5252, 2012.

[20] X. Li, H. Si, J. Z. Niu et al., "Size-controlled syntheses and hydrophilic surface modification of $\mathrm{Fe}_{3} \mathrm{O}_{4}, \mathrm{Ag}$, and $\mathrm{Fe}_{3} \mathrm{O}_{4} / \mathrm{Ag}$ heterodimer nanocrystals," Dalton Transactions, vol. 39, no. 45, pp. 10984-10989, 2010.

[21] R. D. Bennett, A. J. Hart, and R. E. Cohen, "Controlling the morphology of carbon nanotube films by varying the areal density of catalyst nanoclusters using block-copolymer micellar thin films," Advanced Materials, vol. 18, no. 17, pp. 2274-2279, 2006.

[22] Y. M. Li, W. Kim, Y. G. Zhang, M. Rolandi, D. W. Wang, and H. J. Dai, "Growth of single-walled carbon nanotubes from discrete catalytic nanoparticles of various sizes," Journal of Physical Chemistry B, vol. 105, no. 46, pp. 11424-11431, 2001.

[23] H. Kim, J. Kang, Y. Kim, B. H. Hong, J. Choi, and S. Iijima, "Synthesis of ultra-long super-aligned double-walled carbon nanotube forests," Journal of Nanoscience and Nanotechnology, vol. 11, no. 1, pp. 470-473, 2011.

[24] W. Wasel, K. Kuwana, P. T. A. Reilly, and K. Saito, "Experimental characterization of the role of hydrogen in CVD synthesis of MWCNTs," Carbon, vol. 45, no. 4, pp. 833-838, 2007. 

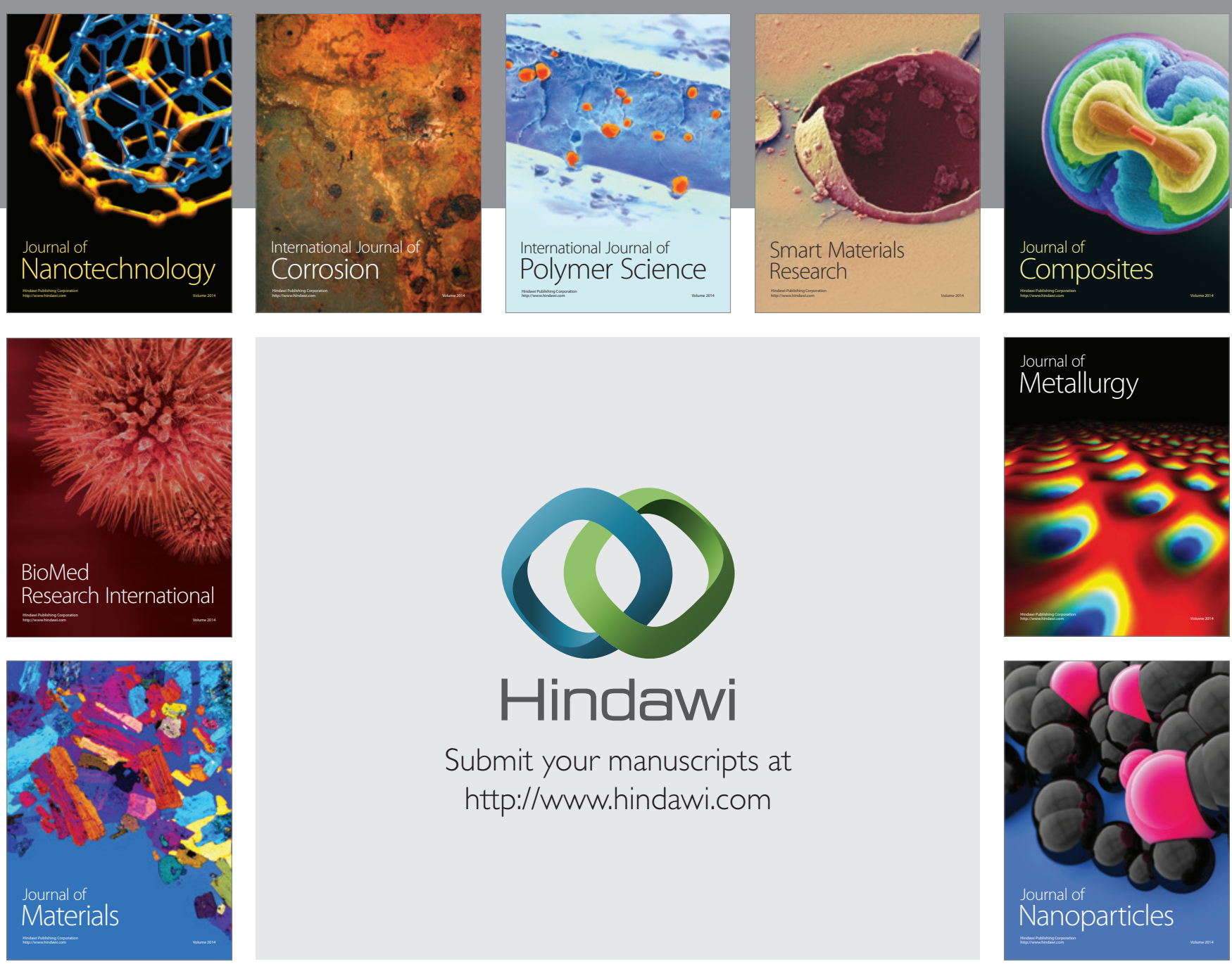

Submit your manuscripts at http://www.hindawi.com
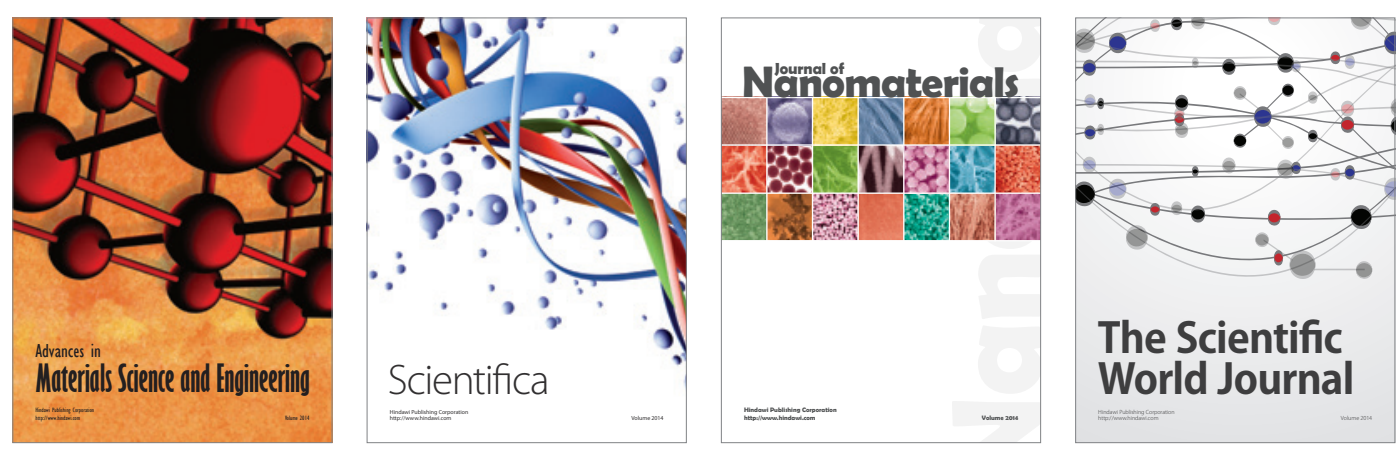

\section{The Scientific World Journal}
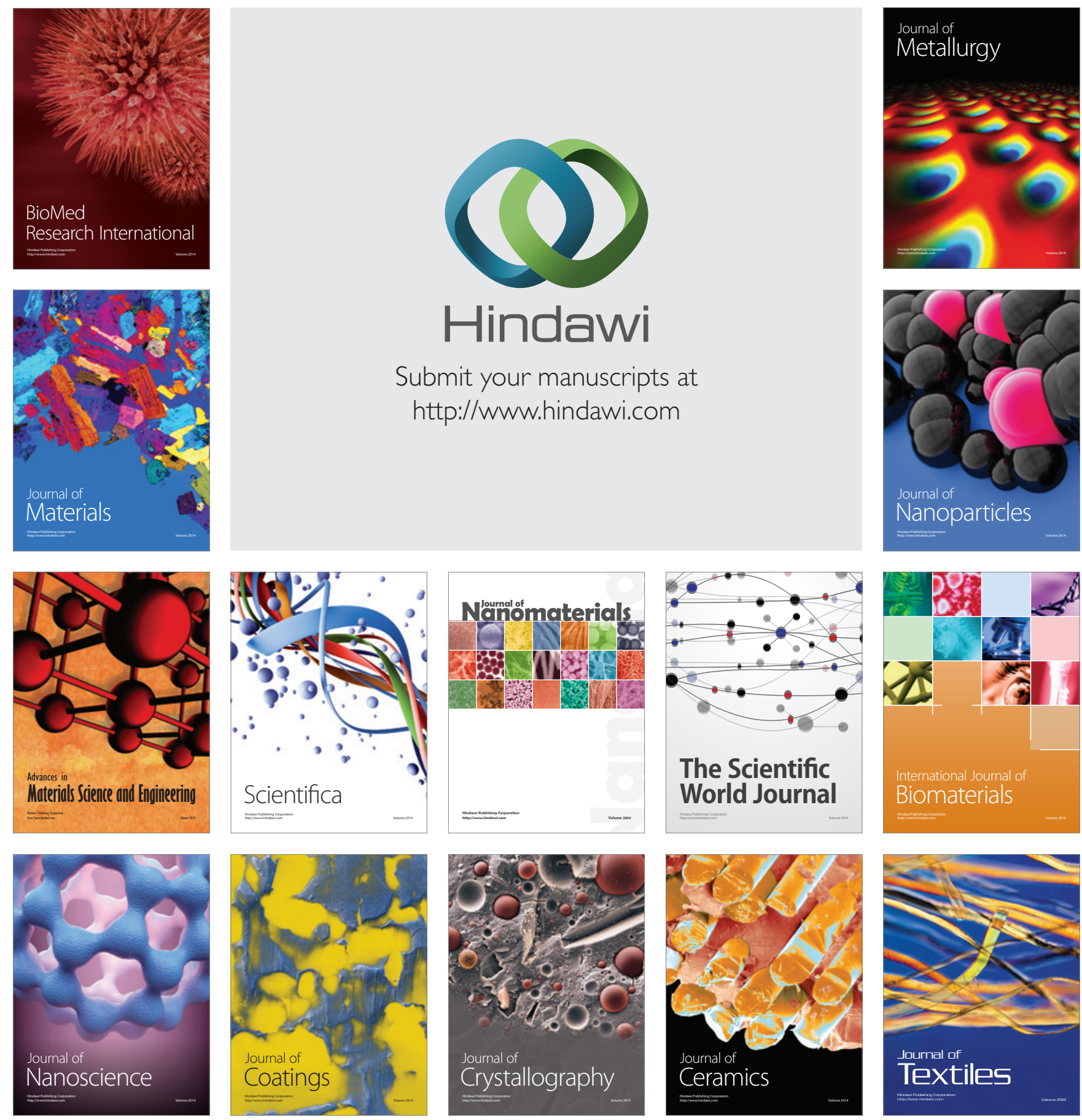